\title{
Pharmacokinetics, Pharmacodynamics, and Safety of the Novel Calcimimetic Agent Evocalcet in Healthy Japanese Subjects: First-in-Human Phase I Study
}

\author{
Tadao Akizawa $^{1} \cdot$ Ryutaro Shimazaki $^{2}$ Masanari Shiramoto ${ }^{3} \cdot$ Masafumi Fukagawa $^{4}$ - Evocalcet Study Group
}

Published online: 30 August 2018

(c) The Author(s) 2018

\begin{abstract}
Background and Objectives Evocalcet is a novel calcimimetic agent with potential to improve the treatment of secondary hyperparathyroidism in patients with chronic kidney disease. This study aimed to determine the pharmacokinetics, pharmacodynamics, and safety of evocalcet in healthy Japanese subjects.

Methods This was a single-blind, placebo-controlled, single-dose study and an 8-day multiple-dose study of evocalcet (MT4580/KHK7580) in 66 healthy Japanese subjects.

Results After a single dose of evocalcet $1-20 \mathrm{mg}$, the time to maximum plasma concentration was attained in $1.5-2 \mathrm{~h}$ (median), and the elimination half-life was 12.98-19.77 $\mathrm{h}$ (mean). Within this dose range, the maximum plasma concentration and area under plasma concentration-time curve increased dose proportionally, confirming linearity. The trough plasma concentrations were relatively unchanged after multiple administration of evocalcet 6 and $12 \mathrm{mg}$. Evocalcet decreased intact parathyroid hormone and corrected calcium and phosphorus levels in a dose-proportional manner. Regarding its safety, no upper gastrointestinal adverse event occurred after the single and multiple administration of evocalcet at doses up to $12 \mathrm{mg}$. Tetany was detected in 1 subject (17\%) after multiple administration of evocalcet $12 \mathrm{mg}$. In healthy subjects, the tolerability and safety of evocalcet were observed for a single dose of evocalcet at doses up to $20 \mathrm{mg}$, and for multiple doses up to $12 \mathrm{mg}$. Conclusions These results suggest that evocalcet may have a comparable efficacy and better safety profile than that of cinacalcet, one of the current treatments for secondary hyperparathyroidism in patients with chronic kidney disease.
\end{abstract}

Electronic supplementary material The online version of this article (https://doi.org/10.1007/s40261-018-0687-4) contains supplementary material, which is available to authorized users.

Tadao Akizawa

akizawa@med.showa-u.ac.jp

1 Division of Nephrology, Department of Medicine, Showa University School of Medicine, Namics 301, 4-24-51

Takanawa, Minato-ku, Tokyo 108-0074, Japan

2 R\&D Division, Kyowa Hakko Kirin Co. Ltd., 1-9-2 Otemachi, Chiyoda-ku, Tokyo 100-0004, Japan

3 SOUSEIKAI Hakata Clinic, Random Square 5-7F, 6-18 Tenyamachi, Hakata-ku, Fukuoka, Fukuoka 812-0025, Japan

4 Division of Nephrology, Endocrinology, and Metabolism, Department of Internal Medicine, Tokai University School of Medicine, 143 Shimokasuya, Isehara, Kanagawa 259-1193, Japan

\section{Key Points for Decision Makers}

The safety and tolerability of single and multiple oral doses of evocalcet administered to healthy Japanese subjects were reported

The pharmacokinetics of evocalcet was considered to be linear (range 1-20 mg evocalcet)

Intact parathyroid hormone and serum calcium levels decreased dose proportionally and remained low with increasing dosages of evocalcet throughout the observation period

Evocalcet may be a novel calcimimetic that has similar efficacy and a better safety profile compared with the currently available cinacalcet hydrochloride 


\section{Introduction}

Chronic kidney disease-mineral and bone disorder (CKD-MBD), an important cause of morbidity and mortality in CKD, includes biochemical abnormalities of calcium, phosphorus, vitamin $\mathrm{D}$, and parathyroid hormone (PTH), associated bone changes, and extra-skeletal ectopic calcification [1]. With the progression of CKD, phosphorus excretion in urine, $1 \alpha$-hydroxylation of vitamin $\mathrm{D}$ in the kidney, and intestinal calcium absorption decrease. One of the most characteristic CKD-MBD morbidities in patients with end-stage renal disease (ESRD) is secondary hyperparathyroidism (SHPT) [2]. Hyperphosphatemia due to SHPT and ESRD is the key stimulator for fibroblast growth factor 23 (FGF23), which is a phosphaturic hormone [3]. However, FGF23 also inhibits $1 \alpha$-hydroxylation of vitamin D, causing low activated vitamin D levels [4]. SHPT causes significant morbidity and mortality in ESRD due to renal osteodystrophy, osteitis fibrosa and heterotopic calcification of soft tissues such as blood vessels, and cardiovascular damage [5,6]. A high and variable prevalence of SHPT (30-50\%) has been reported in stage 5 CKD patients [7]. Treatment of SHPT includes dietary restriction of phosphorus and the prescription of phosphate binders, and/or active vitamin D products. Calcimimetics are an emerging therapy for SHPT in CKD [8-10], allosterically modifying calcium-sensing receptors (CaSR) to reduce PTH secretions [11].

Oral cinacalcet hydrochloride, a calcimimetic agent, is used for SHPT in CKD patients on maintenance dialysis. Cinacalcet acts on CaSR expressed in the parathyroid glands, thereby reducing serum PTH as well as calcium and phosphorus [12]. Unlike activated vitamin D analogues, cinacalcet does not cause an increase in serum calcium and phosphorus. Large-scale clinical trials have shown that cinacalcet improves clinical outcomes and inhibits the onset of cardiovascular events, which are the primary causes of death in patients on dialysis [13-18]. There are safety concerns reported with cinacalcet, which include nausea and vomiting and transient episodes of hypocalcemia [10, 12]. Moreover, cinacalcet potently inhibits cytochrome P450 (CYP) 2D6 and is metabolized by CYP enzymes, primarily $3 \mathrm{~A} 4,2 \mathrm{D} 6$, and $1 \mathrm{~A} 2$; therefore, a potential drug interaction between cinacalcet and CYP2D6 substrates and CYP3A4 inhibitors may exist [19].

Evocalcet (MT-4580/KHK7580), a novel calcimimetic agent, is expected to have an efficacy comparable to that of cinacalcet without causing these safety issues. In a nonclinical study, evocalcet had a dose-proportional PTH-lowering effect and only marginally affected the gastric emptying capacity [20]. Evocalcet is expected to contribute to the attainment of PTH target values even in patients to whom cinacalcet cannot be administered, or for whom the dose cannot be increased to the therapeutically required level, because of adverse reactions; therefore, evocalcet is currently being developed to treat SHPT. We conducted single- and multiple-dose administration studies of evocalcet in healthy, adult Japanese male subjects to assess the pharmacokinetics, pharmacodynamics, and safety of evocalcet.

\section{Methods}

\subsection{Study Design}

Both the single- and multiple-dose studies were placebocontrolled, single-blind studies. Eligible subjects were hospitalized 2 days before the first administration of the investigational drug (Day -2). Subjects received the investigational drug from Day 1 onward and were discharged at the specified dates. In the single-dose administration study, the subjects were scheduled to receive a single oral administration of evocalcet at a dose of $0.3,1,3,6,12$, or $20 \mathrm{mg}$ in a fasting state for $10 \mathrm{~h}$ or more, and to be hospitalized until 3 days after evocalcet administration (Day 4). At each dose, 6 and 2 subjects were randomly assigned to receive evocalcet or placebo, respectively. In the multiple-dose study, the subjects received either $6 \mathrm{mg}$ or $12 \mathrm{mg}$ of evocalcet orally within 30 min after breakfast once daily for 8 days. This study duration was considered to be appropriate for the evaluation of steady-state pharmacokinetics based on the results of the single-dose study. Subjects were hospitalized until 4 days after the final administration (Day 12). At each dose, 6 and 3 subjects were randomly assigned to receive evocalcet or placebo, respectively.

In both studies, the consumption of grapefruit (including food and drink containing grapefruit) and food and drink containing St. John's wort was prohibited from 1 week before the administration of the investigational drug until the end of the study. During the hospitalization period, the consumption of caffeine- and alcohol-containing drinks was prohibited. Smoking was prohibited from 2 weeks before the administration of the investigational drug until discharge, and the use of nicotine-containing anti-smoking drugs was also prohibited.

\subsection{Pharmacokinetic Analysis}

In the single-dose study, blood samples $(2 \mathrm{~mL})$ were collected before the administration of evocalcet $(0 \mathrm{~h})$ and at $0.25,0.5,1,2,3,4,6,8,12,24,36,48$, and $72 \mathrm{~h}$ after administration. Furthermore, urine was pooled from $24 \mathrm{~h}$ 
before the administration of the investigational drug and at $0-4,4-8,8-12,12-24,24-48$, and 48-72 h. Urinary volume was also measured at these time points. In the multipledose study, blood samples $(1 \mathrm{~mL})$ were collected before the administration of evocalcet $(0 \mathrm{~h})$ and at $0.5,1,2,3,4,8$, and $12 \mathrm{~h}$ after administration on Day 1 ; only before administration on Days 2-7; and before the administration of evocalcet (0 h) and at 0.5, 1, 2, 3, 4, 8, 12, 24 (Day 9), 48 (Day 10), 72 (Day 11), and 96 (Day 12) h after administration on Day 8.

\subsection{Bioanalytical Assay}

In both studies, the blood samples were collected in vacuum blood collection tubes containing dipotassium dihydrogen ethylenediaminetetraacetate; they were immediately mixed by inversion and were centrifuged in a cooled centrifuge to obtain plasma. Plasma samples and pooled urine samples were immediately frozen and were stored at $-20^{\circ} \mathrm{C}$ or below until analysis. After extraction from the plasma and urine samples using an OASIS $\mu$ Elution plate (Waters Co., Milford, MA, USA), the concentration of evocalcet was determined using a validated liquid chromatography tandem-mass spectrometry method with a stable isotope-labeled evocalcet as an internal standard (IS). Chromatographic separation was accomplished using either a high-performance (LC-20A) or ultra-fast liquid chromatography system (Shimadzu, Kyoto, Japan) and a Cadenza CD-C18 $(2.0 \mathrm{~mm}$ ID $\times 75 \mathrm{~mm}, 3 \mu \mathrm{m})$ column (Imtakt Corporation, Kyoto, Japan) with a mobile phase containing buffer A (water/formic acid at 1000:1, v/v) and buffer B (acetonitrile/formic acid at 1000:1, v/v) at a flow rate of $0.3 \mathrm{~mL} / \mathrm{min}$. The high-performance liquid chromatography system was coupled to a tandem-mass spectrometer, API 5000 (AB Sciex Pte. Ltd., Concord, ON, Canada), with an electrospray ionization source. The mass spectrometer was operated in the selected reaction monitoring mode. Mass transitions $\left(Q_{1} / Q_{3}\right)$ of $\mathrm{m} / \mathrm{z} 375 / 155$ and $381 / 155$ were used for evocalcet and the IS in positive-ion mode, respectively. In validation tests, precision and accuracy of the method were determined using quality control samples at three concentrations for each matrix: $0.05,10$, and $100 \mathrm{ng} / \mathrm{mL}$ for plasma samples and 0.1 , 10 , and $100 \mathrm{ng} / \mathrm{mL}$ for urine samples. The intra- and interassay accuracy for spiked plasma samples ranged from -10.3 to $3.2 \%$ and -8.9 to $3.8 \%$, respectively. The intra- and interassay precision for spiked plasma samples ranged from 4.0 to $9.2 \%$ and 5.5 to $8.8 \%$, respectively. The intra- and inter-assay accuracy for spiked urine samples ranged from -3.6 to $2.2 \%$ and -3.8 to $1.8 \%$, respectively. The intra- and inter-assay precision for spiked urine samples ranged from 0.7 to $1.8 \%$ and 1.1 to $3.3 \%$, respectively. The lower limit of quantification was $0.05 \mathrm{ng} / \mathrm{mL}$ with a linear calibration range of 0.05 to $100 \mathrm{ng} /$ $\mathrm{mL}$ in plasma samples, whereas in urine samples the lower limit of quantification was $0.1 \mathrm{ng} / \mathrm{mL}$ with a linear calibration range of 0.1 to $100 \mathrm{ng} / \mathrm{mL}$. The samples above the upper limit of quantification were re-analyzed after dilution with the matrix. When the plasma or urine evocalcet concentration was below the lower limit of quantification, the data were handled as $0 \mathrm{ng} / \mathrm{mL}$ when calculating descriptive statistics.

The pharmacokinetic parameters (determined using a noncompartmental method) were calculated for each subject using Phoenix WinNonlin 6.1 software (Pharsight Corporation, Mountain View, CA, USA). The plasma pharmacokinetic parameters evaluated in the single-dose study included maximum plasma concentration $\left(C_{\max }\right)$, time to $C_{\max }\left(t_{\max }\right)$, area under plasma concentration-time curve (AUC), elimination half-life $\left(t_{1 / 2}\right)$, apparent total clearance of the drug from plasma after oral administration $(\mathrm{CL} / F)$, apparent volume of distribution at steady state and terminal phase after nonintravenous administration $\left(V_{\mathrm{z}, \mathrm{ss}} / F\right)$, and the fraction of evocalcet excreted in urine $72 \mathrm{~h}$ after administration. The pharmacokinetic parameters evaluated in the multiple-dose study included the $C_{\max }, t_{\max }, \mathrm{AUC}_{0-24}$, trough plasma concentration $\left(C_{\text {trough }}\right)$, and cumulative coefficient of the $C_{\text {trough }}$ $\left(R_{\mathrm{obs}, C_{\text {trough }}}\right)$ calculated from the $C_{\text {trough }} \cdot R_{\mathrm{obs}, C_{\text {trough }}}$ was calculated using Eq. 1:

$R_{\text {obs, } C_{\text {trough }}}=\frac{C_{\text {trough }} \text { of Day } 8}{C_{\text {trough }} \text { of Day } 1}$

\subsection{Pharmacodynamics}

The pharmacodynamics of evocalcet in both studies was determined from the measurements of intact PTH (iPTH), serum corrected calcium and serum phosphorus. Additionally, laboratory testing was performed to measure ionized calcium, intact FGF23, and urinary calcium. Intact FGF23 was measured using an enzyme-linked immunosorbent assay (FGF23 ELISA Kit; KAINOS Laboratories, Inc., Tokyo, Japan).

\subsection{Safety Analysis}

The safety profile of evocalcet was determined by monitoring adverse events, adverse drug reactions, clinical laboratory values, vital signs, 12-lead electrocardiogram (ECG), and ophthalmological examination.

In the single-dose study, 12-lead ECG was performed before the administration of evocalcet $(0 \mathrm{~h})$ and at 2, 12, 24,48 , and $72 \mathrm{~h}$ after administration. In the multiple-dose study, 12-lead ECG was performed before the administration of evocalcet $(0 \mathrm{~h})$, at 4 and $12 \mathrm{~h}$ after administration on Days 1 and 8, and only before administration on Days 2-7. Twelve-lead ECG was performed also at 24, 48, 72, and $96 \mathrm{~h}$ after administration on Day 8, and performed on Day 15. In addition, subjects continuously wore a 12-lead Holter ECG monitor (H12+; Mortara Instrument, Milwaukee, WI, USA). 
Their heart rate, RR interval, PR interval, QRS interval, QT interval, and QTc interval (QTcF, QTcB) were measured blind at Cardiocore Lab, Inc. at 23.5, 23, 22, 21, 20, 18, 16, and $12 \mathrm{~h}$ before the administration of evocalcet; immediately before administration $(0 \mathrm{~h})$; and at $0.5,1,2,3,4,6,8,12$, and $24 \mathrm{~h}$ after administration in the single-dose study. In the multiple-dose study, the measurements were performed at $22,20,16,12$, and $8 \mathrm{~h}$ before the first administration of evocalcet; immediately before the first administration; 2, 4, 8, 12, and $16 \mathrm{~h}$ after the first administration; before administration on Day 2; before the final administration on Day 8; and at 2, $4,8,12,16,24,36$, and $48 \mathrm{~h}$ after the final administration.

In both studies, an ophthalmological examination was performed using a slit lamp before the start of administration and on Day 4 (single-dose study) or Day 12 (multipledose study) after the final administration. This examination was performed because multiple administrations of a calcimimetic such as evocalcet or cinacalcet can cause particulate opacity of the lens due to decreased calcium levels (unpublished data). Vital signs (blood pressure, pulse rate, and body temperature) were measured at specified time points as well.

\section{Results}

\subsection{Study Populations}

In the single-dose study, a manufacturing issue affected the quality of the $0.1 \mathrm{mg}$ capsules after administration of evocalcet had started. Therefore, although the $0.3 \mathrm{mg}$ dose was used throughout the study, the pharmacokinetic and pharmacodynamic data from this group were used as observational values only, and the pharmacokinetic and pharmacodynamic parameters were determined for 42 subjects in the other groups. Table 1 shows the disposition of 60 healthy Japanese men (aged 20-39 years; body mass index: $18.5 \mathrm{~kg} / \mathrm{m}^{2}$ to $\left.<25.0 \mathrm{~kg} / \mathrm{m}^{2}\right)$ in the single- $(n=42)$ and multiple-dose $(n=18)$ studies. In the multiple-dose group, evocalcet was discontinued in 1 subject in the 12-mg group, 3 days after the start of the administration.

\subsection{Pharmacokinetics}

In the single-dose study, the plasma drug level after the administration of evocalcet reached $t_{\max }$ at $1.5-2 \mathrm{~h}$ (median) after administration and showed biphasic changes; the mean $t_{1 / 2}$ was $12.98-19.77 \mathrm{~h}$ (Fig. 1a; Table 2). At this dosage, the $C_{\max }$ and AUC increased dose proportionally (Table 2 ). In both groups, the fraction of evocalcet excreted in the urine was $<0.1 \%$ of the dose.

Figure $1 \mathrm{~b}$ shows the changes in the plasma drug levels in the multiple-dose study. On Day 1, the median $t_{\max }$ values were 3.83 and $3.60 \mathrm{~h}$ in the 6- and 12-mg groups, respectively; the mean $C_{\max }$ values were 393 and $898 \mathrm{ng} /$ $\mathrm{mL}$, respectively; and the mean $\mathrm{AUC}_{0-24}$ was 3447.1 and $8517.8 \mathrm{ng} \cdot \mathrm{h} / \mathrm{mL}$, respectively (Table 3). On Day 8, the final day of administration, the changes in the plasma levels were similar to those on Day 1 in both the 6- and 12-mg groups. The mean $C_{\text {trough }}$ values $24 \mathrm{~h}$ after administration on Days $1-8$ were $46.0-69.9 \mathrm{ng} / \mathrm{mL}$ in the $6-\mathrm{mg}$ group and $108-166 \mathrm{ng} / \mathrm{mL}$ in the $12-\mathrm{mg}$ group (Table 3 ). The $R_{\text {obs, } C_{\text {trough }}}$ were 0.95 and $0.97 \mathrm{ng} / \mathrm{mL}$ in the 6 - and $12-\mathrm{mg}$ groups, respectively (Table 3).

Table 1 Subject demographics (single- and multiple-dose studies)

\begin{tabular}{|c|c|c|c|c|c|c|c|c|c|}
\hline \multirow[t]{2}{*}{ Characteristic } & \multicolumn{6}{|c|}{ Single-dose study } & \multicolumn{3}{|c|}{ Multiple-dose study } \\
\hline & Placebo & $1 \mathrm{mg}$ & $3 \mathrm{mg}$ & $6 \mathrm{mg}$ & $12 \mathrm{mg}$ & $20 \mathrm{mg}$ & Placebo & $6 \mathrm{mg}$ & $12 \mathrm{mg}$ \\
\hline$n$ & 12 & 6 & 6 & 6 & 6 & 6 & 6 & 6 & 6 \\
\hline Age & $\begin{array}{l}23.7 \\
(20,28)\end{array}$ & $\begin{array}{l}22.3 \\
(21,25)\end{array}$ & $\begin{array}{l}23.3 \\
(20,27)\end{array}$ & $\begin{array}{l}22.3 \\
(20,28)\end{array}$ & $\begin{array}{l}20.8 \\
(20,24)\end{array}$ & $\begin{array}{l}28.5 \\
(20,35)\end{array}$ & $\begin{array}{l}23.8 \\
(20,29)\end{array}$ & $\begin{array}{l}23.5 \\
(20,36)\end{array}$ & $\begin{array}{l}23.5 \\
(20,32)\end{array}$ \\
\hline BMI & $\begin{array}{l}20.7 \\
(18.8,23.6)\end{array}$ & $\begin{array}{l}21.8 \\
(18.9,24.5)\end{array}$ & $\begin{array}{l}20.8 \\
(19.0,23.2)\end{array}$ & $\begin{array}{l}21.1 \\
(19.0,23.0)\end{array}$ & $\begin{array}{l}21.9 \\
(18.6,24.6)\end{array}$ & $\begin{array}{l}22.8 \\
(21.1,23.7)\end{array}$ & $\begin{array}{l}21.8 \\
(18.6,24.0)\end{array}$ & $\begin{array}{l}21.1 \\
(19.8,22.3)\end{array}$ & $\begin{array}{l}21.9 \\
(19.5,23.7)\end{array}$ \\
\hline $\begin{array}{c}\text { Intact PTH } \\
(\mathrm{pg} / \mathrm{mL})\end{array}$ & $\begin{array}{l}37.6 \\
(25,52)\end{array}$ & $\begin{array}{l}32.2 \\
(22,41)\end{array}$ & $\begin{array}{l}37.2 \\
(31,46)\end{array}$ & $\begin{array}{l}34.2 \\
(17,47)\end{array}$ & $\begin{array}{l}36.3 \\
(30,43)\end{array}$ & $\begin{array}{l}34.0 \\
(23,46)\end{array}$ & $\begin{array}{l}33.8 \\
(25,42)\end{array}$ & $\begin{array}{l}29.0 \\
(24,37)\end{array}$ & $\begin{array}{l}31.0 \\
(25,42)\end{array}$ \\
\hline $\begin{array}{c}\text { Corrected } \\
\text { calcium } \\
(\mathrm{mg} / \mathrm{dL})\end{array}$ & $\begin{array}{l}9.12 \\
(8.8,9.4)\end{array}$ & $\begin{array}{l}9.33 \\
(9.1,9.6)\end{array}$ & $\begin{array}{l}9.08 \\
(8.9,9.3)\end{array}$ & $\begin{array}{l}9.08 \\
(8.8,9.4)\end{array}$ & $\begin{array}{l}9.10 \\
(9.0,9.4)\end{array}$ & $\begin{array}{l}9.17 \\
(9.0,9.4)\end{array}$ & $\begin{array}{l}9.13 \\
(8.8,9.5)\end{array}$ & $\begin{array}{l}9.03 \\
(8.8,9.3)\end{array}$ & $\begin{array}{l}9.13 \\
(8.9,9.4)\end{array}$ \\
\hline $\begin{array}{c}\text { Phosphorus } \\
\text { (mg/dL) }\end{array}$ & $\begin{array}{l}4.08 \\
(3.4,4.6)\end{array}$ & $\begin{array}{l}4.18 \\
(3.8,4.9)\end{array}$ & $\begin{array}{l}4.30 \\
(4.1,4.7)\end{array}$ & $\begin{array}{l}3.98 \\
(3.6,4.2)\end{array}$ & $\begin{array}{l}4.05 \\
(3.9,4.3)\end{array}$ & $\begin{array}{l}3.92 \\
(3.4,4.5)\end{array}$ & $\begin{array}{l}4.23 \\
(3.8,4.7)\end{array}$ & $\begin{array}{l}4.12 \\
(3.5,4.7)\end{array}$ & $\begin{array}{l}4.55 \\
(4.1,5.0)\end{array}$ \\
\hline
\end{tabular}

Data are the mean (minimum, maximum)

$B M I$ body mass index, $P T H$ parathyroid hormone 

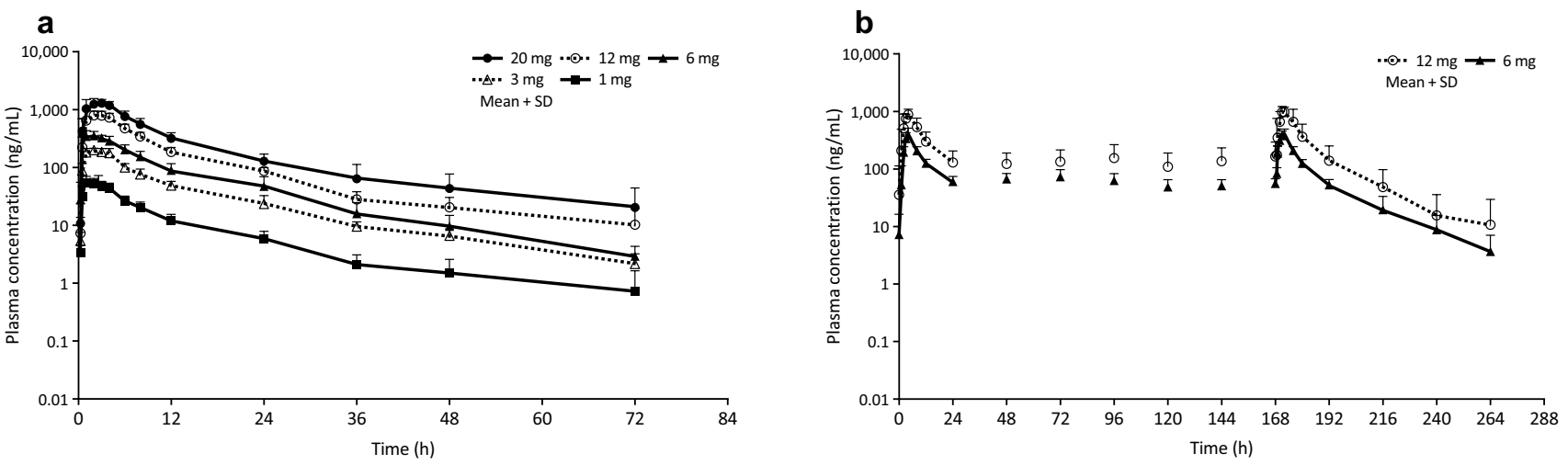

Fig. 1 Plasma concentration-time profiles after single (a) and multiple doses (b) of evocalcet in healthy subjects. Error bars represent standard deviations

Table 2 Pharmacokinetic parameters of single-dose plasma evocalcet

\begin{tabular}{llcclccc}
\hline Dose $(\mathrm{mg})$ & $n$ & AUC $(\mathrm{ng} \cdot \mathrm{h} / \mathrm{mL})$ & $C_{\max }(\mathrm{ng} / \mathrm{mL})$ & $t_{\max }(\mathrm{h})$ & $t_{1 / 2}(\mathrm{~h})$ & $\mathrm{CL} / F(\mathrm{~L} / \mathrm{h})$ & $V_{\mathrm{z}} / F(\mathrm{~L})$ \\
\hline 1 & 6 & $601.6 \pm 170.3$ & $59 \pm 13$ & $1.5(1.0-3.0)$ & $19.77 \pm 13.82$ & $1.8 \pm 0.6$ & $44.8 \pm 19.7$ \\
3 & 6 & $2239.7 \pm 269.5$ & $217 \pm 24$ & $1.5(1.0-3.0)$ & $17.32 \pm 6.74$ & $1.4 \pm 0.2$ & $34.3 \pm 13.9$ \\
6 & 6 & $4038.5 \pm 1154.7$ & $376 \pm 54$ & $1.5(1.0-2.0)$ & $14.76 \pm 2.74$ & $1.6 \pm 0.5$ & $34.6 \pm 13.5$ \\
12 & 6 & $8855.8 \pm 991.2$ & $867 \pm 109$ & $2.0(1.0-3.0)$ & $12.98 \pm 4.91$ & $1.4 \pm 0.2$ & $25.2 \pm 8.4$ \\
20 & 6 & $15307.4 \pm 4442.1$ & $1400 \pm 240$ & $2.0(1.0-3.0)$ & $18.89 \pm 8.95$ & $1.4 \pm 0.4$ & $35.3 \pm 11.3$ \\
\hline
\end{tabular}

Values are the mean \pm SD

$n$ number of subjects used to calculate summary statistics, $t_{\max }$ median (min, max)

$A U C$ area under plasma concentration-time curve, $C_{\max }$ maximum plasma concentration, $t_{\max }$ time to maximum plasma concentration $\left(C_{\max }\right), t_{1 / 2}$ terminal half-life, $C L / F$ apparent plasma clearance of drug after extravascular administration, $V / F$ apparent volume of distribution in the elimination phase

Table 3 Pharmacokinetic parameters of multiple-dose plasma evocalcet

\begin{tabular}{llllllllll}
\hline Dose $(\mathrm{mg})$ & Day & $n$ & $\mathrm{AUC}_{0-24}(\mathrm{ng} \cdot \mathrm{h} / \mathrm{mL})$ & $C_{\max }(\mathrm{ng} / \mathrm{mL})$ & $t_{\max }(\mathrm{h})$ & $C_{\text {trough }}(\mathrm{ng} / \mathrm{mL})$ & $t_{1 / 2}(\mathrm{~h})$ & $\mathrm{CL} / F(\mathrm{~L} / \mathrm{h})$ & $R_{\text {obs}, C_{\text {trough }}}$ \\
\hline 6 & Day 1 & 6 & $3447.1 \pm 721.3$ & $393 \pm 118$ & $4.0(3.0-4.0)$ & $57.0 \pm 15.7$ & - & - & - \\
& Day 8 & 6 & $3860.6 \pm 643.3$ & $394 \pm 97$ & $4.0(2.0-4.0)$ & $51.1 \pm 14.6$ & $18.50 \pm 3.76$ & $1.6 \pm 0.3$ & $0.95 \pm 0.35$ \\
12 & Day 1 & 6 & $8517.8 \pm 2599.6$ & $898 \pm 182$ & $4.0(2.0-4.0)$ & $129 \pm 71$ & - & - & - \\
& Day 8 & 6 & $10836.3 \pm 4690.7$ & $1050 \pm 250$ & $3.0(2.0-8.0)$ & $141 \pm 110$ & $16.30 \pm 5.24$ & $1.3 \pm 0.6$ & $0.97 \pm 0.34$ \\
\hline
\end{tabular}

Values are the mean \pm SD

$n$ number of subjects used to calculate summary statistics, $t_{\max }$ median (min, max)

$A U C$ area under plasma concentration-time curve, $C_{\max }$ maximum plasma concentration, $t_{\max }$ time to maximum plasma concentration $\left(C_{\max }\right)$, $C_{\text {trough }}$ trough plasma concentration, $t_{I / 2}$ terminal half-life, $C L / F$ apparent plasma clearance of drug after extravascular administration, $R_{\text {obs }, C_{\text {trough }}}$ cumulative coefficient of the $C_{\text {trough }}$ values

\subsection{Pharmacodynamics}

\subsection{1 iPTH}

As shown in Fig. 2a, the percent change in iPTH levels from baseline started to decrease $0.5 \mathrm{~h}$ after the administration of evocalcet and reached the lowest levels $1-4 \mathrm{~h}$ after the administration of the single dose. At the time of the lowest iPTH levels within that time range, the percent changes from baseline in the placebo group and in the 1-, 3-, 6-, 12-, and 20-mg groups were $-20.79 \%,-51.73 \%,-64.73 \%,-75.10 \%$, $-70.50 \%$, and $-70.45 \%$, respectively, mostly showing a doseproportional decrease. Thereafter, as the dose increased, there was a tendency for low iPTH levels to persist.

In the multiple-dose study, iPTH levels decreased after the administration of $6 \mathrm{mg}$ and $12 \mathrm{mg}$ evocalcet and reached the lowest levels at 3-4 $\mathrm{h}$ after administration, returning to the baseline levels by Day 2 (Fig. 2b). Trough iPTH levels on Days 2-7 remained at baseline levels, with no difference between treatment groups. Thereafter, the iPTH level 

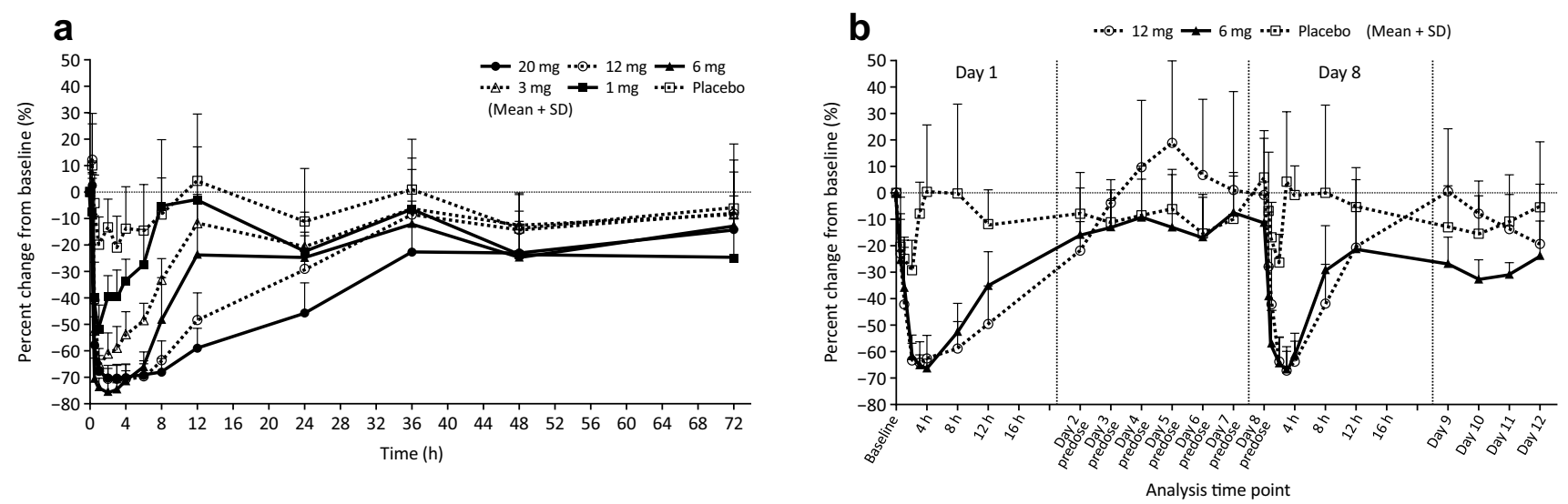

Fig. 2 Percent change in intact parathyroid hormone concentration in the single-dose study (a) and the multiple-dose study (b). Error bars represent standard deviations

changes on Day 8 were similar to those on Day 1, returning to the baseline levels by Day 9 . Furthermore, the changes in the iPTH levels were similar in the 6- and 12-mg groups.

\subsubsection{Corrected Calcium}

As shown in Fig. 3a, b, the extent of the change in corrected calcium levels from baseline started to decrease after administration of evocalcet and reached the lowest levels at 12-24 $\mathrm{h}$ after administration in the single-dose study, and during Day 1 (placebo) or Day 8 (6 mg and $12 \mathrm{mg}$ evocalcet) after administration in the multiple-dose study.

In the single-dose study, at the time point of lowest levels, the percent changes in the placebo group and the 1-, 3-, 6-, 12- (at $12 \mathrm{~h}$ ), and $20-\mathrm{mg}$ (at $24 \mathrm{~h}$ ) groups were $-3.15 \%$, $-5.34 \%,-8.25 \%,-10.63 \%,-12.63 \%$, and $-15.09 \%$, respectively. Similar to what was observed for the iPTH levels, corrected calcium decreased and tended to persist in a dose-proportional manner.
In the multiple-dose study, at the time points at which levels were the lowest, the extent of changes in the placebo group and the 6- and 12-mg groups between Days $1-2$ were $-3.05 \%,-9.21 \%$, and $-14.40 \%$, respectively (Fig. 3b). Although the values did not return to baseline values $24 \mathrm{~h}$ after administration on Day 1 (before the administration of the investigational drug on Day 2), the trough corrected calcium levels on Days 2-7 were constant. At the time point at which the corrected calcium level was the lowest between Days $8-9$ (i.e. $8 \mathrm{~h}$ after administration on Day 8 ), the percent changes were $-1.44 \%,-15.68 \%$, and $-19.40 \%$ in the placebo and evocalcet 6-mg and 12-mg groups, respectively, with all groups showing a greater decrease than was measured on Day 1 . The level of decrease was greater in the 12-mg evocalcet group than in the 6-mg evocalcet group. The values returned to baseline on Day 11 or 12, 3-4 days after final administration of the investigational drug. a

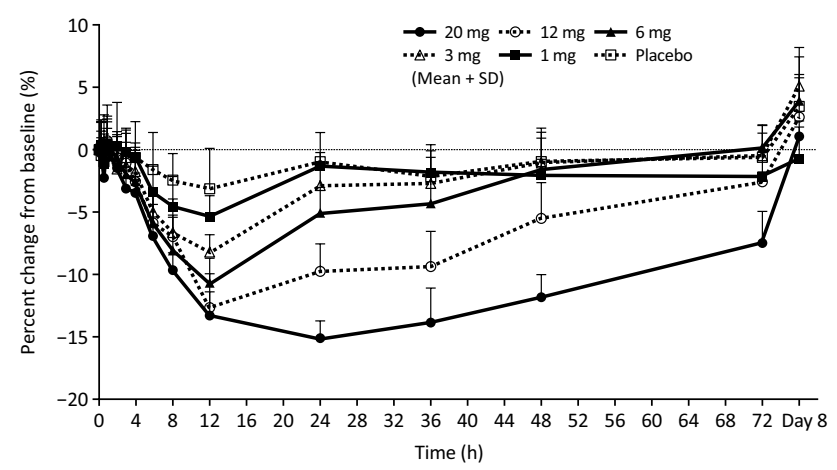

b

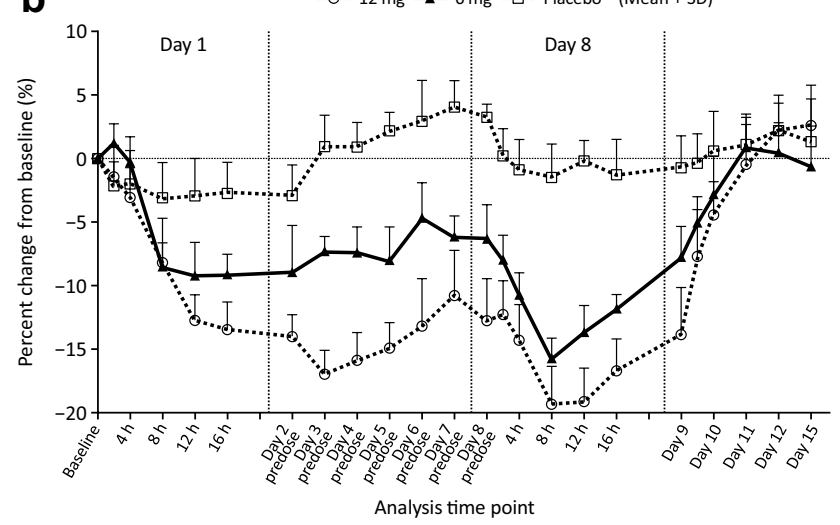

Fig. 3 Percent change in corrected calcium concentration in the single-dose study (a) and the multiple-dose study (b). Error bars represent standard deviations 


\subsubsection{Phosphorus}

In all groups in the single-dose study, phosphorus decreased until $6 \mathrm{~h}$ after administration, began to increase at $8 \mathrm{~h}$, and peaked at $12 \mathrm{~h}$ (Fig. 4a) probably due to the decrease in PTH. At this peak, the percent changes from baseline in the placebo group and in the 1-, 3-, 6-, 12-, and 20-mg groups were $-9.73 \%,-1.53 \%,-1.50 \%, 2.53 \%, 7.86 \%$, and $15.45 \%$, respectively. In the evocalcet groups there was a tendency towards high phosphorus values in a dose-proportional manner.

In the multiple-dose study, phosphorus at Day 1 and Day 8 temporarily declined after administration and recovered to the baseline at $16 \mathrm{~h}$ after administration in both groups (Fig. 4b). In the evocalcet groups, phosphorus increased throughout the administration period and recovered to the baseline after the administration period ended.

\subsubsection{Other Laboratory Testing}

The ionized calcium levels showed changes similar to those of the corrected calcium levels (Supplemental Fig. S1a). Urinary calcium excretion increased dose proportionally 4-8 $\mathrm{h}$ after evocalcet administration, returning to baseline levels 12-24 h after administration (Supplemental Fig. S1b). As shown in Supplemental Fig. S2, similar to the iPTH and corrected calcium, intact FGF23 levels decreased and persisted in a dose-proportional manner after the administration of evocalcet.

\subsection{Safety}

In the single administration study, tonsillitis was observed in 1 subject (17\%) in the $0.3-\mathrm{mg}$ evocalcet group, and gastrointestinal disorders were observed in 2 subjects (33\%) in the 20-mg evocalcet group. All gastrointestinal disorders were determined to be adverse reactions, including abdominal discomfort and nausea and vomiting [1 subject (17\%) each]. No adverse events occurred in the 1-12-mg evocalcet groups. In the multiple-dose study, no adverse events occurred in the placebo group or the 6-mg evocalcet group; however, tetany (moderate) occurred in 1 subject (17\%) in the $12-\mathrm{mg}$ evocalcet group, 3 days after the start of administration. The administration of the investigational drug was discontinued on the same day. This event was considered to be associated with decreased calcium caused by evocalcet; it was therefore considered to be an adverse drug reaction. This adverse drug reaction disappeared and resolved with the administration of calcium gluconate hydrate, 2 days after the onset of the adverse event.

The 12-lead ECG results are presented in Figs. 5 and 6. In both studies, a non-significant QTcF prolongation at increasing evocalcet doses was observed. Neither findings were clinically significant or determined to be an adverse event. Changes in the baseline QTcF are negatively correlated with corrected calcium levels. In both studies, there were no clinically significant findings in the ophthalmological examination.

\section{Discussion}

The single- and multiple-dose studies described here are the first clinical studies of evocalcet, and these provide important insights for the pharmacokinetics, pharmacodynamics, and safety of the drug. After a single dose of 1-20 mg evocalcet, the $t_{1 / 2}$ was $12.98-19.77 \mathrm{~h}$ and was similar at all doses tested. The $C_{\max }$ and AUC increased dose proportionally. Accordingly, the pharmacokinetics of evocalcet after a single dose shows linearity in the 1-20 mg dose range. The bioavailability of evocalcet in rats was over $80 \%$, showing higher bioavailability than that of cinacalcet (1-2\%) [20]. In a previous
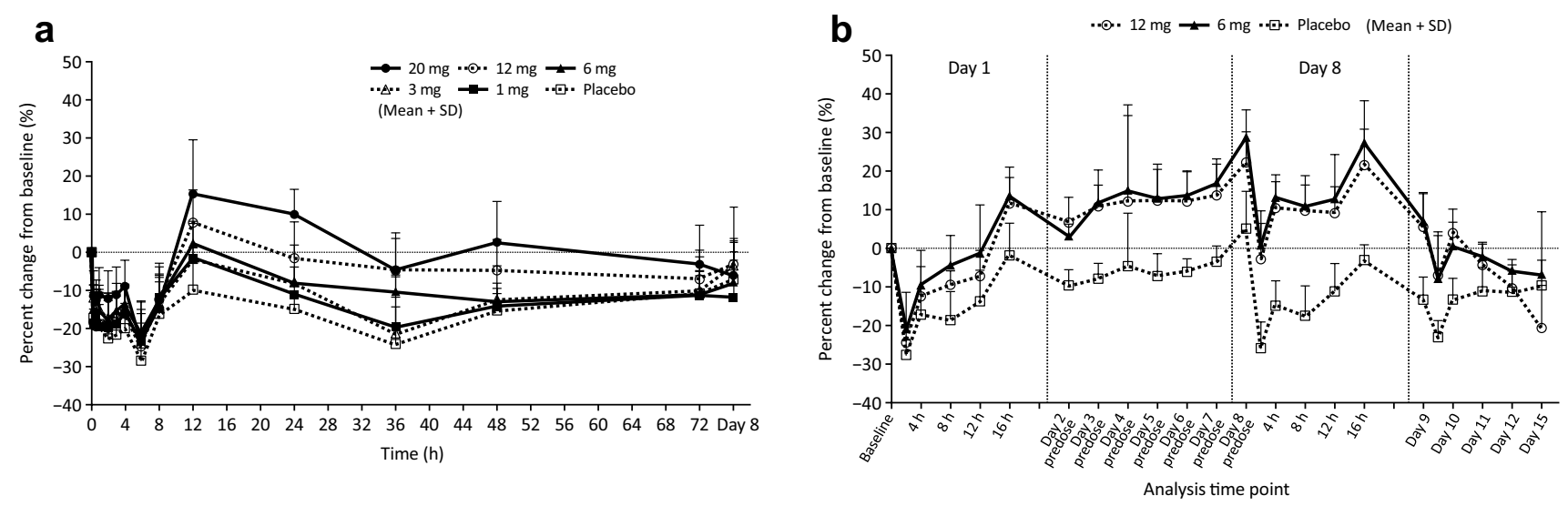

Fig. 4 Percent change in phosphorus concentration in the single-dose study (a) and the multiple-dose study (b). Error bars represent standard deviations 

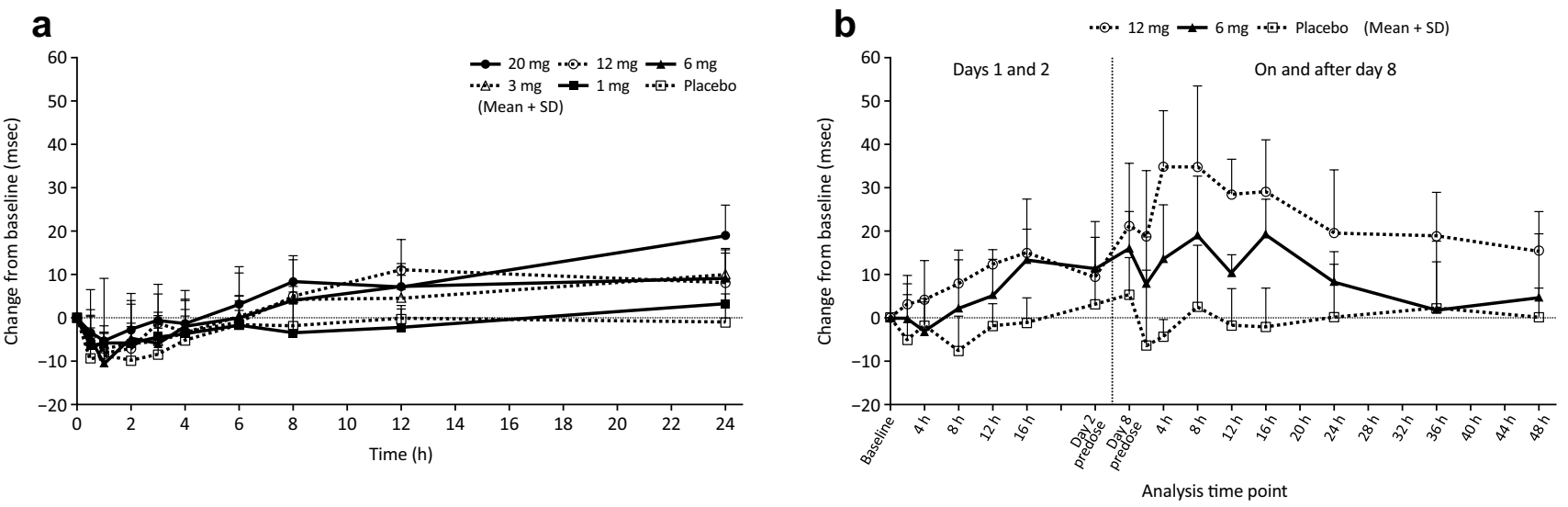

Fig. 5 Change from baseline in QTc interval (QTcF) in the single-dose study (a) and the multiple-dose study (b). Error bars represent standard deviations

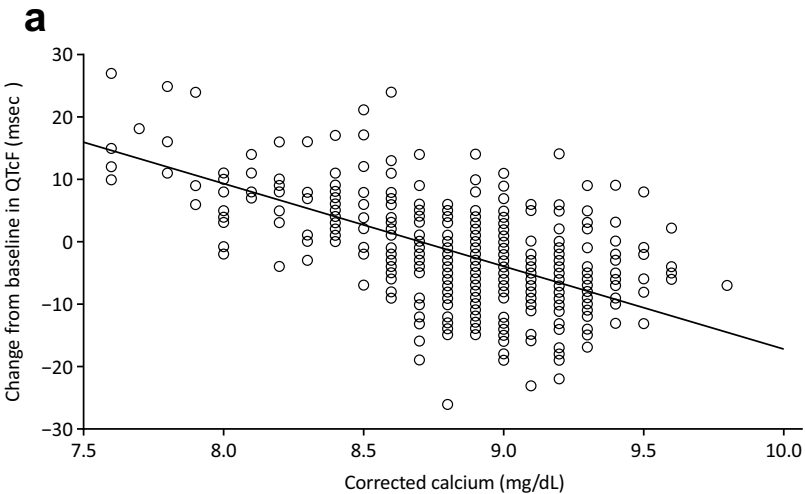

Fig. 6 Correlation between the change in QTc interval (QTcF) and corrected calcium concentration in the single-dose study (a) and the multiple-dose study (b). Regression equation in the single-dose study: change from baseline in $\mathrm{QTcF}=115.70-13.31 *$ corrected calcium.

study in healthy Chinese subjects $(n=42)$, the pharmacokinetics, pharmacodynamics, and safety of cinacalcet were determined. With single doses of 25,50 , and $100 \mathrm{mg}$ cinacalcet, the mean (standard deviation) $C_{\max }$ and $\mathrm{AUC}_{0 \text {-last }}$ values were 7.68 (4.25), 17 (6.33), and $31.3(16.42) \mathrm{ng} / \mathrm{mL}$, and 58.4 (25.38), 187 (70.7), and 367 (180.03) ng.h/mL, respectively. The $C_{\max }$ and AUC after administration of $1 \mathrm{mg}$ evocalcet were $58.8 \mathrm{ng} / \mathrm{mL}$ and $567.0 \mathrm{ng} \cdot \mathrm{h} / \mathrm{mL}$, respectively. This suggests that the exposure of evocalcet in humans may be higher at lower doses than that of cinacalcet. In the multiple-dose study, the $C_{\text {trough }}$ values were relatively unchanged at Days $1-8$, showing no accumulation. Similarly, no accumulation has been reported for cinacalcet [21].

After the administration of evocalcet, iPTH levels and corrected calcium levels decreased mostly in a doseproportional manner, remaining at constant low levels at increasing doses, demonstrating that evocalcet had a

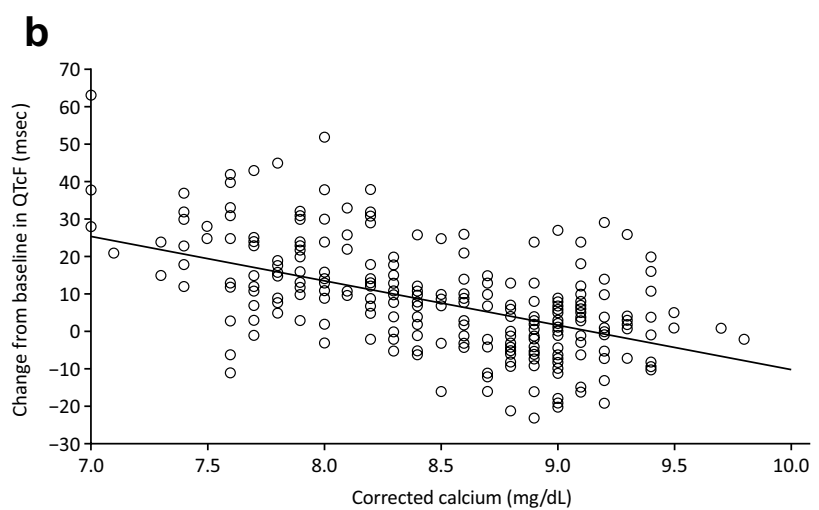

90\% confidence interval for coefficient of corrected calcium: -15.10 to -11.51 . Regression equation in the multiple-dose study: change from baseline in $\mathrm{QTcF}=108.73-11.91 *$ corrected calcium. $90 \%$ confidence interval for coefficient of corrected calcium: -14.77 to -9.04

pharmacological effect similar to that of cinacalcet [22]. In a previous study, after the single administration of $25 \mathrm{mg}$ cinacalcet to healthy Japanese adults, the lowest iPTH was approximately $15 \mathrm{pg} / \mathrm{mL}$ ( $4 \mathrm{~h}$ after administration), as compared with approximately $30 \mathrm{pg} / \mathrm{mL}$ before administration [23]. The corresponding value after a single administration of $1 \mathrm{mg}$ evocalcet in the present study was $15.0 \mathrm{pg} / \mathrm{mL}(1 \mathrm{~h}$ after administration) as compared with $32.2 \mathrm{pg} / \mathrm{mL}$ before administration. Consequently, a therapeutic effect may be attained with a lower dose of evocalcet than of cinacalcet.

In the present single-dose study, iPTH levels reached the lowest levels 1-4 h after administration, and corrected calcium levels subsequently reached the lowest levels $12-24 \mathrm{~h}$ after the administration of evocalcet. In the single- and multiple-dose studies, the decrease in and duration of corrected calcium levels were dose-proportional. In the multiple-dose study of $12 \mathrm{mg}$ evocalcet, tetany occurred in 1 subject (17\%) 
as an adverse drug reaction. This was resolved along with the recovery of the corrected calcium level after the administration of calcium gluconate hydrate. Accordingly, it was considered to be attributable to the calcium-lowering effect unique to calcimimetics [24].

As defined in the ICH-E14 guideline [25], evaluation of QT prolongation is necessary in the development of low-molecular weight compounds, particularly at the early stages of the clinical development phase. Decreased serum calcium causes QT prolongation [26]. Accordingly, calcimimetics with serum calcium-lowering effects may cause QT prolongation, and cinacalcet has indeed been reported to cause QT prolongation [27]. In the single- and multiple-dose assessments in the current study, evocalcet prolonged the QTcF in a dose-proportional manner. Because changes in the baseline QTcF are negatively correlated with corrected calcium levels, QTcF prolongation caused by evocalcet might have been a secondary effect due to decreased serum calcium (Fig. 6).

In the current study, evocalcet was shown to be safe in both the single- and multiple-dose assessments. Tonsillitis occurred in one subject (17\%) receiving a single dose of evocalcet $0.3 \mathrm{mg}$. Gastrointestinal disorder occurred in two subjects (33\%) receiving single doses of evocalcet $20 \mathrm{mg}$. With the exception of these two adverse events in the evocalcet $20 \mathrm{mg}$ dose group, no gastrointestinal disorders occurred in subjects receiving a single dose or multiple doses of evocalcet. In nonclinical studies, evocalcet has been confirmed to only slightly inhibit gastric emptying, as compared with that observed for cinacalcet, suggesting that evocalcet may have a wider safety range when used in patients with gastrointestinal disorders [20].

Evocalcet showed no clinically significant changes in laboratory tests, vital signs, 12-lead ECG, and ophthalmological examinations at doses up to $20 \mathrm{mg}$ in the single-dose study and up to $12 \mathrm{mg}$ in the multiple-dose study, indicative of its safety and tolerability.

Calcimimetics like evocalcet reduce PTH, restore mineral metabolism, enhance adherence, are safe for use, and may help to improve long-term outcomes in patients with CKD on dialysis. The efficacy and safety of these agents should be further explored in appropriately designed clinical studies in this target subject population. CaSR modulation is an effective approach to control SHPT. Interactions of this class of agent with other therapeutic options in CKD-MBD should be further explored in additional independent trials in the future.

\section{Conclusions}

The pharmacokinetics of evocalcet in the single-dose study showed linearity in the dose range of 1-20 mg, and no accumulation was observed in the multiple-dose study on Days
1-8. Aspects of the pharmacodynamics of evocalcet, such as the PTH- and serum calcium-lowering effects, may be reached at a lower dose than that of cinacalcet. In addition, evocalcet was safe and tolerable at doses up to $20 \mathrm{mg}$ in the single-dose study and up to $12 \mathrm{mg}$ in the once daily, 8-day multiple-dose study. No gastrointestinal disorders occurred at a dose of $12 \mathrm{mg}$ evocalcet in the multiple-dose study; accordingly, evocalcet may cause fewer upper gastrointestinal symptoms than is observed for cinacalcet. The efficacy and safety of evocalcet as a calcimimetic agent should be assessed in further clinical studies.

Acknowledgements We thank Dr Tarveen Jandoo, MD, MBA, of Edanz Medical Writing for providing medical writing support.

Author contributions All authors participated in the conception and design of the study, and contributed to acquisition, analysis, and interpretation of data. TA drafted the manuscript; RS, MS, and MF revised the paper critically for important intellectual content. All authors approved the final version of the manuscript.

\section{Compliance with Ethical Standards}

Conflict of interest TA has received consulting fees from Kyowa Hakko Kirin Co. Ltd., Astellas Pharma Inc., Bayer Yakuhin, Ltd., Fuso Pharmaceutical Industries, Ltd., Japan Tobacco Inc., Ono Pharmaceutical Co. Ltd. and NIPRO Industry, and lecture fees from Kyowa Hakko Kirin Co. Ltd., Chugai Pharmaceutical Co. Ltd., Bayer Yakuhin, Ltd., Kissei Pharmaceutical Co. Ltd., Torii Pharmaceutical Co. Ltd. and Ono Pharmaceutical Co. Ltd. MF has received consulting fees from Kyowa Hakko Kirin Co. Ltd. and Ono Pharmaceutical Co. Ltd.; lecture fees from Kyowa Hakko Kirin Co. Ltd., Bayer Yakuhin, Ltd., Torii Pharmaceutical Co. Ltd. and Ono Pharmaceutical Co. Ltd.; and grants from Kyowa Hakko Kirin Co. Ltd. and Bayer Yakuhin, Ltd. MS has no conflicts of interest to declare. RS is employed by Kyowa Hakko Kirin Co. Ltd., which funded this research.

Ethics approval Prior to the start of the single-dose and multiple-dose studies, the study protocols were approved by the Hakata Clinic Institutional Review Board. The study was conducted in compliance with the International Ethical Guidelines for Biomedical Research Involving Human Subjects, Good Clinical Practice Guidelines, the Declaration of Helsinki, and local laws.

Funding This study was sponsored by Kyowa Hakko Kirin Co. Ltd. Medical writing and editorial support was funded by Kyowa Hakko Kirin Co. Ltd.

Informed consent All subjects provided written informed consent. The study was conducted at the Hakata Clinic, Fukuoka, Japan.

Open Access This article is distributed under the terms of the Creative Commons Attribution-NonCommercial 4.0 International License (http://creativecommons.org/licenses/by-nc/4.0/), which permits any noncommercial use, distribution, and reproduction in any medium, provided you give appropriate credit to the original author(s) and the source, provide a link to the Creative Commons license, and indicate if changes were made. 


\section{References}

1. Moorthi RN, Moe SM. CKD-mineral and bone disorder: core curriculum 2011. Am J Kidney Dis. 2011;58(6):1022-36.

2. Cunningham J, Locatelli F, Rodriguez M. Secondary hyperparathyroidism: pathogenesis, disease progression, and therapeutic options. Clin J Am Soc Nephrol. 2011;6:913-21.

3. Nabeshima Y. Clinical discovery of alpha-Klotho and FGF-23 unveiled new insight into calcium and phosphate homeostasis. Calcium. 2008;18:923-34.

4. Melamed ML, Buttar RS, Coco M. CKD-mineral bone disorder in stage 4 and 5 CKD: what we know today? Adv Chronic Kidney Dis. 2016;23(4):262-9.

5. Cianciolo G, Capelli I, Cappuccilli M, et al. Calcifying circulating cells: an uncharted area in the setting of vascular calcification in CKD patients. Clin Kidney J. 2016;9(2):280-6.

6. Fernández M, Morales E, Gutierrez E, et al. Calciphylaxis: beyond CKD-MBD. Nefrologia. 2017;37(5):501-7.

7. Hedgeman E, Lipworth L, Lowe K, Saran R, Do T, Fryzek J. International burden of chronic kidney disease and secondary hyperparathyroidism: a systematic review of the literature and available data. Int J Nephrol. 2015;2015:184321.

8. Wetmore JB, Quarles LD. Treatment of secondary hyperparathyroidism in kidney disease: what we know and do not know about use of calcimimetics and vitamin D analogs. Int J Nephrol Renovasc Dis. 2008;1:5-17.

9. Palmer SC, Gardner S, Tonelli M, et al. Phosphate-binding agents in adults with CKD: a network meta-analysis of randomized trials. Am J Kidney Dis. 2016;68(5):691-702.

10. Stubbs JR, Wetmore JB. Does it matter how parathyroid hormone levels are suppressed in secondary hyperparathyroidism? Semin Dial. 2011;24:298-306.

11. Drüeke TB. Calcimimetics and outcomes in CKD. Kidney Int Suppl. 2013;3(5):431-5.

12. Torres PU. Cinacalcet HCl: a novel treatment for secondary hyperparathyroidism caused by chronic kidney disease. J Ren Nutr. 2006;16(3):253-8

13. Raggi P, Chertow GM, Torres PU, et al. The ADVANCE study: a randomized study to evaluate the effects of cinacalcet plus lowdose vitamin $\mathrm{D}$ on vascular calcification in patients on hemodialysis. Nephrol Dial Transpl. 2011;26(4):1327-39.

14. Ureña-Torres PA, Floege J, Hawley CM, et al. Protocol adherence and the progression of cardiovascular calcification in the ADVANCE study. Nephrol Dial Transpl. 2013;28:146-52.
15. Chertow GM, Block GA, Correa-Rotter R, et al. Effect of cinacalcet on cardiovascular disease in patients undergoing dialysis. N Engl J Med. 2012;367:2482-94.

16. Fukagawa M, Fukuma S, Onishi Y, et al. Prescription patterns and mineral metabolism abnormalities in the cinacalcet era: results from the MBD-5D study. Clin J Am Soc Nephrol. 2012;7(9):1473-80.

17. Karohl C, Raggi P. Cinacalcet: will it play a role in reducing cardiovascular events? Future Cardiol. 2012;8(3):357-70.

18. Akizawa T, Kurita N, Mizobuchi M, et al. PTH-dependence of the effectiveness of cinacalcet in hemodialysis patients with secondary hyperparathyroidism. Sci Rep. 2016;6:19612.

19. Padhi D, Harris R. Clinical pharmacokinetic and pharmacodynamic profile of cinacalcet hydrochloride. Clin Pharmacokinet. 2009;48(5):303-11.

20. Kawata T, Tokunaga S, Murai M, et al. A novel calcimimetic agent, evocalcet (MT-4580/KHK7580), suppresses the parathyroid cell function with little effect on the gastrointestinal tract or CYP isozymes in vivo and in vitro. PLoS One. 2018;13(4):e0195316.

21. Liu H, Wang H, Liu T, Jiang J, Chen X, Gao F, Hu P. Pharmacokinetic and pharmacodynamic properties of cinacalcet (KRN1493) in Chinese healthy volunteers: a randomized, open-label, single ascending-dose and multiple-dose, parallel-group study. Clin Ther. 2016;38(2):348-57.

22. Barman Balfour JA, Scott LJ. Cinacalcet hydrochloride. Drugs. 2005;65(2):271-81.

23. Azuma J, Furuya Y, Uchida E. Phase I study of KRN1493 (cinacalcet hydrochloride) in healthy male volunteers-pharmacokinetics, pharmacodynamics and safety after single oral dosing. Jpn Pharmacol Ther. 2007;35:953-62.

24. Wüthrich RP, Martin D. Bilezikian JP. The role of calcimimetics in the treatment of hyperparathyroidism. Eur J Clin Investig. 2007;37(12):915-22.

25. Shah RR. Drugs, QT interval prolongation and ICH E14: the need to get it right. Drug Saf. 2005;28(2):115-25.

26. So CS, Batrice L, Volger E. Electrocardiographic changes in electrolyte inbalance. Part 2: alterations in serum calcium (author's transl). Med Klin. 1975;70(48):1966-8.

27. Temiz G, Yalçın AU, Mutluay R, Bozacı İ, Bal C. Effects of cinacalcet treatment on QT interval in hemodialysis patients. Anatol J Cardiol. 2015. https://doi.org/10.5152/anatoljcardiol.2015.6284. 